\title{
Entre o Mercado e o Fórum: o debate anti-tabagismo na cena midiática
}

\author{
Daniela Santiago ${ }^{1}$ \\ Uni-BH \\ santiagodaniela@uol.com.br \\ Rousiley C. M. Maia ${ }^{2}$ \\ Universidade Federal de Minas Gerais \\ rousiley@fafich.ufmg.br
}

\begin{abstract}
Resumo: Este artigo tem como propósito abordar a inter-relação existente entre os complexos empresariais internacionais e as esferas públicas de sociedades democráticas específicas. Para tanto, investigase o debate público, na cena midiática, em torno da problemática do fumo - motivado pela tramitação da Lei Antitabagista (Lei no 10.167/oo) - , procurando compreender de que forma o cenário mais amplo das discussões de interesse público motivou adequações e limites aos planos mercadológicos da empresa. A quase interdição do processo de construção de marcas pela lei tem impacto direto na mediação simbólica entre a empresa e seus públicos, além de alterar o perfil de concorrência e atuação no mercado. Busca-se investigar, de modo particular, o modo pelo qual a empresa Souza Cruz dialogou com os demais atores sociais, num cenário de grandes adversidades, revestindo suas práticas de elementos discursivos que lhe permitiam legitimar-se frente a demandas políticas, éticas e morais, que transcendem, em muito, o domínio estrito da racionalidade econômica.
\end{abstract}

Palavras-chave: debate público; esfera pública; propaganda; tabagismo

\begin{abstract}
This article has the purpose of approaching the existent interrelation between the international managerial compounds and the public spheres of specific democratic societies. For such, public debate is investigated, in the mediatic scene, regarding the problem of tobaccospurred by the processing of the Anti-tobacco Law (Law in the 10.167/oo)-, attempting to understand those forms in the widest scenery of the discussions of public interest which motivated adaptations and limits to the marketing plans of the company. The quasi
\end{abstract}

\footnotetext{
${ }^{1}$ Daniela Santiago é mestre em Comunicação Social pela Universidade Federal de Minas Gerais e professora do Departamento de Ciências da Comunicação do Uni-BH. ${ }^{2}$ Rousiley C. M. Maia é doutora em Ciência Política pela University of Nottingham e professora do Departamento Social da UFMG.
} 
interdiction of the process of construction of marks for the law has direct impact in the symbolic mediation between the company and its publics, besides altering the competition profile and performance in the market. We seek to investigate, the way on behalf of which the Souza Cruz company dialogued, with the other social actors, in a private way, in a scenery of great adversities, covering up its practices of discursive elements which allowed legalizing in face of political, ethical demands, and its existence, transcending, on the whole, the strict domain of the economical rationality.

Key words: public debate; public sphere; advertisement; tobacco

Résumé: Le propos de cet article est d'aborder l'interface existante entre les complexes d'entreprises internationales et la sphère publique des sociétés démocratiques spécifiques. Pour cela, le débat public est analysé, dans les médias, autour de la problématique du tabac-motivé par la votation de la Loi Antitabac (Loi no. 10.167/oo) - dans le dessein de comprendre de quelle manière le scénario des discussions d'intérêt public le plus vaste, déclencha des adéquations et des limites dans les prospections de marché des entreprises. La quasi-interdiction par la loi du procès de création de marques a un impact direct sur la médiation symbolique entre l'entreprise et ses publics et de surcroît, elle modifie le profil de la concurrence et l'activité du marché. L'investigation, de manière particulière, se focalise sur la façon par laquelle l'entreprise Souza Cruz établit un dialogue avec tous les acteurs sociaux, dans un scénario de grandes adversités en parant ses pratiques d'éléments discursifs qui lui certifiaient sa légitimité face aux demandes politiques, éthiques et morales, en transcendant davantage, le strict domaine de la rationalité économique.

Mots-clés: débat public, sphère publique, publicité, tabac

Resumen: Este artículo tiene por objeto acercarse a la interrelación existente entre los compuestos directivos internacionales y las esferas públicas de sociedades democráticas específicas. Por este motivo, el debate público se investiga, en la escena mediática, con respecto al problema causado por el tabaco en lo que va a la Ley Anti-tabaco ( Ley 10.167/oo) -, intentando entender esas formas en la esfera más amplia de las discusiones de interés público que motivó adaptaciones y límites a los planes del mercadeo de la compañía. La casi interdicción del proceso de construcción de marcas para la ley tiene impacto directo en la mediación simbólica entre la compañía y sus públicos, además de alterar el perfil de la competición y actuación en el mercado. Nosotros buscamos investigar, la manera en que la compañía Souza y Cruz dialogó, con los otros actores sociales, de una manera privada, en un paisaje de grandes adversidades, las que cubre sus prácticas de elementos discursivos que permitieron legalizar ante las demandas políticas, éticas, y su existencia, transcendiendo, en general, el dominio estricto de la racionalidad económica.

Palabras claves: Debate público; esfera pública; propaganda, tabaco 
Nas sociedades complexas contemporâneas, a mídia pode ser entendida como uma instância em que boa parte das controvérsias públicas se desenvolve. Enquanto aparato técnico, os meios de comunicação proporcionam um espaço de visibilidade em que imagens, proferimentos, ações e eventos tornam-se disponíveis para o conhecimento comum, de modo “público, compartilhado e socialmente acessível”, como Dewey (1927) escreveu. Em estudos sobre comunicação política, o papel que os meios de comunicação desempenham como fórum de debate cívico - arena de disputa de interesse e de troca de razões mediando o Estado e os cidadãos, e também entre esses - vem despertando crescente interesse (Meyer, 1995; Klandermans e Goslinga, 1996; Page,1996; Camauër, 2000; Norris, 2000; Reese et al. 2003). Os agentes da mídia editam e enquadram as vozes dos agentes sociais, através de modos operatórios próprios, produzindo o cruzamento de discursos advindos de diversos setores sociais (Entman, 1993; Curran, 2001; Gomes, 2004; McCombs e Ghanem, 2003). Aquilo que é tornado "público" pela mídia atinge uma audiência ilimitada, espaçotemporalmente dispersa, e promove múltiplos caminhos para a conversação cívica

Políticos e porta-vozes de determinadas causas, bem como atores da sociedade civil empreendem uma "luta por visibilidade", a fim de influenciar a publicização dos eventos pelos agentes da mídia, buscando controlar as percepções que os cidadãos têm de questões de interesse coletivo (Gamson, 1992; Ryan, 1991; MacAdam, 1996; Plot, 1999; Pan e Kosicki, 2003). Por certo, o acesso desses atores aos meios de comunicação é fortemente regulado pelos profissionais da mídia, seguindo rotinas produtivas e padrões empresariais configurados pelos imperativos de lucro do mercado, na maioria dos casos. Além disso, os atores sociais têm recursos altamente diferenciados para transacionar com os agentes da mídia, seja em termos organizacionais e econômicos, seja em termos de recursos simbólicos, de prestígio e notoriedade. Contudo, o fator publicidade proporciona restrições à 
transposição direta do poder econômico de grandes empresas para formas de poder político, capaz de fazer valer os interesses específicos das corporações em detrimento da vontade ou das necessidades mais amplas da sociedade.

Autores deliberacionistas vêm defendendo que a complexidade da sociedade contemporânea não impede processos coletivos de debate. Ao lado da coordenação sistêmica e da ação de especialistas, a participação de públicos críticos da sociedade civil em debates públicos amplia a base de conhecimentos para o processamento coletivo e contínuo de problemas, e proporciona, também, maior legitimidade para as decisões das instâncias estatais (Bohman, 2000; Drysek, 2002; Habermas, 1997). Nesse processo, destaca-se a importância do intercâmbio permanente entre as esferas públicas formais e informais na deliberação, principalmente para corrigir as pressões de fontes não democráticas de poder sobre as tomadas de decisão institucional. Assim sendo, é fundamental que o debate torne-se mais amplo possível nas sociedades complexas, inclusive, através da visibilidade proporcionada pela mídia massiva.

Neste artigo, pretende-se evidenciar que o poder dos centros decisórios do sistema político, face aos complexos empresariais, se torna mais sólido quando sustentado por públicos críticos na periferia do sistema político. A partir de tal perspectiva, pretende-se apreciar a experiência vivenciada pelas empresas tabagistas diante de legislações anti-tabagistas, particularmente a lei número 10.167/oo sancionada em dezembro de 2000, que define limites para as estratégias mercadológicas das empresas. A produção, a comercialização e o consumo do cigarro compreendem questões controversas, com implicações muitas vezes éticas e morais que extrapolam os domínios de relevância exclusiva da esfera convencionalmente considerada 'econômica'. Assim sendo, o interesse particular, neste artigo, é examinar o embate discursivo sobre a legislação anti-fumo interno à cena midiática, identificando os argumentos que ganham visibilidade, as principais estratégias discursivas 
utilizadas pelos atores sociais no espaço da mídia, bem como o modo pelo qual a própria mídia construiu seus enquadramentos discursivos no cenário nacional.

Nesse sentido, entendemos que o fórum de debates promovido pelos meios de comunicação é um entre vários outros espaços discursivos sobre determinados temas existentes nas sociedades democráticas (Blumer e Gurevitch, 2000; Norris, 2000; Reese et al. 2003). Contudo, o espaço da mídia dispõe de amplo poder de publicidade, uma vez que é dirigido a um público abrangente, incluindo potencialmente todos os cidadãos. Tal característica impõe modificações importantes à dinâmica argumentativa. No espaço de visibilidade midiática, os discursos interagem de forma complexa, formando uma rede difusa de discursos. Isso porque os agentes da mídia promovem a mediação de instituições e esferas distintas, de modo que um grande número de considerações - que correspondem a diferentes esferas de validade, bem como a diferentes posições de interesse e valor - vêm a público (Page, 1996; Maia, 2004; Bohman, 1999, 2000).

De tal sorte, partimos da premissa de que existe um "potencial público" para a razão na cena midiática e múltiplos agentes podem dar voz a um espectro diverso de razões públicas, de modos distintos e com graus variados na articulação de seus discursos: alguns salientam questões de eficácia, outros, questões de bem viver, éticas e morais. Nesse âmbito, o interesse específico do artigo é buscar entender como as companhias produtoras de cigarro dialogam com outros atores sociais participantes do debate sobre o fumo, na cena midiática, detectando o seu posicionamento diante do produto que comercializa e as tentativas de legitimar seus posicionamentos argumentativos frente aos demais.

Para cumprir tais propósitos, elaborou-se uma estratégia analítica estruturada em dois planos. Foram examinadas, em primeiro lugar, matérias jornalísticas de 3 jornais diários de circulação nacional - Folha de S. Paulo, 
Estado de Minas e Jornal do Brasil -, no período de janeiro de 2000 a dezembro de 20013. Este período compreende: (1) a fase anterior ao envio do projeto de lei à Câmara dos Deputados; (2) sua tramitação no Congresso Nacional, entre os meses de junho e dezembro de 2000 e (3) o período posterior à publicação da Lei no 10.167/oo, ocorrida em 27 de dezembro de 2000, e seus desdobramentos. A partir do material jornalístico, buscou-se apreender a estratégia discursiva utilizada pelos principais agenciadores do discurso das empresas - particularmente a Souza Cruz - na polêmica em torno do fumo. Em segundo lugar, buscou-se detectar o impacto geral do debate público no projeto de fala da empresa4. Para tanto, os principais argumentos apresentados pela Companhia Souza Cruz em seu site na internet foram aproximados daqueles defendidos pelos principais interlocutores envolvidos pelo debate anti-tabagismo, os quais ganharam visibilidade nas matérias veiculadas pela mídia.

\section{Complexidade, conglomerados transnacionais e controle democrático}

Tornou-se senso comum afirmar que a ordem mundial atual é mais aberta, complexa, incerta, diversa, interconectada e passível de desencadear riscos que qualquer época anterior - sendo este um repertório comum utilizado nos discursos sobre a globalização. É preciso ressaltar, contudo, que a própria noção de globalização - embora muito utilizada em discursos acadêmicos e populares - é extremamente vaga e ambígua (Giddens, 2001; Schmalz-Bruns, 2001; Guibernau, 2001). Pode-se falar de uma globalização econômica, ao fazer referência a transações econômicas que se movimentam num nível nunca antes atingido, com a aceleração de mercados financeiros e a

\footnotetext{
${ }^{3}$ Das matérias sobre a temática do tabagismo veiculadas nos jornais selecionados, foi selecionado um corpus composto por 266 matérias que tratavam de um embate argumentativo explícito.

${ }^{4}$ Projeto de fala refere-se, neste contexto, não só à competência comunicativa dos sujeitos falantes - a responsabilidade e a capacidade de organizar enunciados - como também às estratégias utilizadas para alcançar certos objetivos comunicativos, tais como factivo, informativo, persuasivo e sedutor (Charaudeau, 1996)
} 
influência de empresas transnacionais por meio de cadeias de produção mundiais, que afetam, de modo imediato e mediato, as economias nacionais. Nesse âmbito, a noção de globalização pode referir-se, também, à formação da economia global, que não se deixa regular por qualquer domínio específico, na medida em que os circuitos financeiros se tornam autônomos e se desdobram segundo uma dinâmica própria. Contudo, a globalização econômica não pode ser apreendida como "uma imagem estática, de uma política de múltiplas camadas dentro de uma organização mundial”, como alerta Habermas (2000, p.139), mas, sim, mediante "uma imagem dinâmica das interferências e interações entre os processos políticos que se desenvolvem de modo peculiar nos âmbitos nacional, internacional e global”.

A Companhia Souza Cruz é líder absoluta no mercado de cigarros no Brasil, e subsidiária do segundo maior conglomerado tabagista do mundo, a British American Tocacco (BAT), com participação no mercado mundial de $14,6 \%$. Com mais de 3000 marcas em seu portifólio, a empresa atinge todas as partes do mundo e é líder de mercado em 50 dos 180 mercados em que atua5. O conglomerado possui 85 fábricas em 66 países, empregando mais de $85 \mathrm{mil}$ pessoas. Em seu site na Internet ${ }^{6}$, a BAT afirma gerar mais de 100 mil empregos indiretos, sendo que os impostos relativos ao cigarro correspondem à maior parte das receitas governamentais em quase todos os países. No Brasil, a participação chega a $6 \%$ do total da receita do Estado.

A BAT é estrategicamente planejada para atuar no mercado global. Desde sua criação contou com um perfil internacional, operando fora tanto da Grã-Bretanha quanto dos Estados Unidos. A cadeia de produção e distribuição encontra-se tecnicamente fragmentada e as forças produtivas básicas -

\footnotetext{
5 A atuação da BAT encontra-se dividida em 5 regiões: "America-Pacific" (Canadá, Estados Unidos, Japão e Coréia do Sul); "Asia-Pacific" (China, sul da Ásia incluindo Índia, sudeste da Ásia e Austrália), "Latin América and Caribean" (paises da América do Sul, México, América Central e Caribe), Europe (compreendendo mais de 40 países) e "África and Middle East".

${ }^{6}$ http://www.bat.com. Acesso em 10/07/2003.
} 
compreendendo capital, tecnologia e força de trabalho - mostram-se dispersas num plano transnacional, ultrapassando fronteiras geográficas, históricas e culturais (Ianni, 1999; Santos, 2001). Não obstante, todo o processo de gestão encontra-se integrado por um sofisticado planejamento coorporativo, ou seja, as ações de logística desenvolvidas localmente são articuladas como parte de um processo conjunto de ganhos globais. Nas palavras de Milton Santos, trata-se de uma unidade política de comando, que funciona no interior das firmas e não uma mera unidade de gerência do mercado global: "cada empresa comanda as respectivas operações dentro da sua respectiva topografia, isto é, do conjunto de lugares de sua ação” (Santos, 2001, p.27). De tal sorte, o conglomerado e as empresas podem decidir estrategicamente sobre zonas de atuação, levando em consideração fatores como custo de matéria prima e mão de obra, facilidades de infra-estrutura, questão fiscal, entre outros. As vantagens competitivas são cuidadosamente planejadas no nível nacional, regional e mundial.

Nesse cenário, muitos autores se mostram céticos com a possibilidade da deliberação pública, do uso da razão em público vir a se impor frente ao poderio econômico de conglomerados transnacionais (Leader, 2001). Alguns críticos tendem a defender que os complexos transnacionais, conforme estruturados na fase atual da globalização, não seriam capazes de sobrepor-se aos complexos estatais (Streeck apub Schmalz-Bruns, 2001; Chesneaux, 1995). A empresa global, em virtude de seu poder, poderia preocupar-se, simplesmente, com a boa articulação de sua política mercadológica, sem necessitar dialogar com outros domínios sociais, exceto quando estes lhe fossem úteis na estruturação de suas ações estratégicas. Outros críticos tratam a sintonia entre os sistemas e os sub-sistemas do mercado como um problema de coordenação funcional, e, assim, tendem a expurgar a dimensão moral e ética das regulamentações (Zolo, 1992). Seria esse um processo de coordenação às cegas, exterior à ordem normativa estabelecida e negociada no plano cotidiano da vida social. 
Apesar de tal ceticismo, nossa premissa é a de que o debate público, e “o intercâmbio de razões em público" (Cohen, 1997), pode ser direcionado para solução de problemas complexos que afetam de modos distintos os atores sociais e que, para serem resolvidos, requerem a cooperação entre eles, fazendo emergir novas atitudes e orientações políticas, e, também, novas relações entre os cidadãos e as instituições de uma dada sociedade. Nesse esteio, interessa-nos observar a inter-relação existente entre os complexos empresariais internacionais e as esferas públicas de sociedades democráticas específicas. Como apontado, buscaremos abordar, no caso do debate antitabagismo na cena midiática, o modo pelo qual os atores econômicos, muito mais que lidarem com suas estratégias produtivas e mercadológicas, são obrigados a revestir tais práticas de elementos discursivos que lhes permitam legitimar-se face às demandas éticas, políticas e sociais, que transcendem, em muito, o domínio estrito da racionalidade econômica.

\section{A lei 10.167/oo e a interdição do projeto de fala empresarial}

O projeto de construção de marcas - enquanto a identidade que se quer dar à mercadoria, e sua divulgação através de propagandas publicitárias - é um dos pilares fundamentais da estratégia mercadológica das empresas globais. As marcas são mediadores simbólicos importantes entre a empresa e seus públicos (Zozzoli, 1998, p. 56; Klein, 2002, p.141). Elas possuem a capacidade de integrar as ações produtivas descentradas das empresas globais, além de alterar o perfil de concorrência e a atuação no mercado (Santos, 2001, p.49). Face a este papel primordial desempenhado pela marca, em especial na atual fase da globalização, seria possível uma empresa permanecer ou crescer no mercado, principalmente no de consumo de massa, sem o recurso da propaganda?

Esta é a pergunta fundamental que as empresas de cigarro têm o desafio de responder, frente ao crescente número de legislações anti-fumo, que têm imposto diversas limitações aos seus projetos de fala. Em muitos 
países, as empresas tabagistas tiveram seu projeto de construção de marca quase totalmente interditado. No Brasil, desde dezembro de 2000, as companhias de cigarro podem somente utilizar-se da propaganda nos pontos de venda. Campanha em qualquer meio de comunicação, patrocínio, merchandising, promoção, enfim, todos os mecanismos de divulgação de marca foram proibidos pela lei no 10.167/00.

A nosso ver, tal limitação não pode ser simplesmente qualificada como uma adversidade à qual a empresa pudesse responder unicamente mobilizando uma estratégia tecno-eficiente, a fim de alcançar suas metas com sucesso no campo mercadológico. As legislações são frutos da institucionalização do debate público sobre o cigarro, que mobiliza agentes de diferentes esferas e subsistemas, com demandas e interesses diversos. Sobre esse contexto, as empresas têm pouco ou nenhum controle. Esta situação se configura de modo bastante diverso daquela com a qual as companhias usualmente se deparam quando da estruturação de seu modelo produtivo e buscam o maior controle possível sobre as variáveis envolvidas, seguindo máximas decisórias determinadas para si mesmos em suas áreas de atuação. No espaço público, ao invés disso, a presença dos atores articula-se na perspectiva do participante. Por conseguinte, o sucesso de um determinado interlocutor numa situação de debate não pode ser alcançado de modo isolado. O público que debate questões de interesse coletivo não o faz a partir exclusivamente de sua própria opinião, mas como participante de uma razão pública (Bohman, 1999; Cohen, 1997). Assim, as proposições apresentadas não podem ser racionalizadas apenas sob o aspecto técnico, pois envolvem também uma perspectiva moral prática que impõe a exigência de serem compreensíveis e potencialmente aceitáveis pelos demais parceiros do debate os argumentos apresentados, através da cooperação dialógica.

Além disso, interessa ressaltar, para os propósitos deste trabalho, que a vigência das legislações antitabagismo em diversos países, dentre eles o Brasil, 
não deve ser vista como resultado apenas da ação do Estado sobre o mercado. Não se trata de ignorar que a imposição de normas jurídicas é obviamente uma prerrogativa do Estado constitucional, parte do conjunto de suas funções de organização e execução da lei. O Estado conta com uma aparelhagem que inclui instrumentos de poder para aplicar sanções, caso algum ator social não corresponda às determinações presentes no corpo da lei. Entretanto, supervalorizar o papel do Estado como agente exclusivo da regulamentação acaba produzindo uma perspectiva de exterioridade, de uma instituição que age sobre a outra. Tal perspectiva mostra-se insuficiente se atentarmos para o fato de que a conservação da eficácia da lei, para além do curto prazo, dependerá de processos de legitimação em que as regras vêm a ser aceitas como justas e, em geral, apoiadas por aqueles que dela participam. "Não é a forma do direito, enquanto tal, que legitima o exercício do poder político, e, sim, a ligação com o direito legitimamente estatuído (Habermas, 1997, p.170).

Nesse sentido, a legitimidade da lei exige a negociação entre sujeitos sociais, dentro do próprio ordenamento do Estado Democrático, tanto em órgãos parlamentares e em tribunais quanto em esferas públicas diversas, organizadas de modo informal em torno de temas específicos, que se estruturam com diferentes graus de organização, densidade comunicativa e alcance na sociedade. Assim, autores deliberacionistas, preocupados com a organização democrática das instituições, sustentam que a pretensão de legitimidade e de racionalidade dos arranjos legais e respectivas configurações institucionais não podem prescindir da contribuição da sociedade civil (Benhabib, 1996; Bohman, 2000, Drysek, 2002).

Esta é uma das teses centrais do modelo de circulação de poder político (two track-model) desenvolvido por Habermas em Direito e Democracia. A sociedade deve contar com instituições plurais, suficientemente flexíveis, para garantir o processo deliberativo através de intercâmbios vibrantes entre os públicos e as organizações democráticas. Em outros termos, o Estado requer 
constantemente inputs do público para que possa detectar problemas sociais e disfunções funcionais que se refletem na vida cotidiana; bem como para processar problemas que não podem ser resolvidos sem a cooperação do público de cidadãos. Para manter a legitimidade nas decisões, esses inputs não podem ser ignorados pelos agentes administrativos do próprio Estado e nem por especialistas envolvidos na implementação de políticas públicas. Para produzir opinião qualificada e racionalizada, o público, por sua vez, não pode formar-se sem os métodos e os limites das instituições democráticas. Como Bohman propõe,

A cooperação democrática é mais exigente que a mera obediência, requerida em formas super-complexas de organização e de integração social. Nesses sistemas extremante complexos que requerem alto grau de obediência, eles tornam-se vulneráveis para serem organizados pelos atores públicos que reabrem o quadro da deliberação sobre certos problemas e sobre as soluções técnicas correntes" (Bohman, 2000, p.192).

Nesse sentido, o debate antitagista estendeu-se a muitos contextos diferentes, perpassando o âmbito transnacional e seguindo uma dinâmica própria no cenário nacional. Tal debate incluiu segmentos variados da sociedade, em fóruns de discussão diversos, com maior ou menor grau de organização, desde fóruns científicos - encontros promovidos pela OMS, pelo Ministério da Saúde, Instituto Nacional do Câncer, envolvendo especialistas tanto da área de saúde como da área jurídica - até encontros promovidos por associações como Centro de Apoio ao Tabagista e grupos de auto-ajuda em que os indivíduos afetados, procurando livrar-se do vício, compartilham suas vivências e suas histórias de vida.

Cabe ressaltar o papel da publicidade nesse processo. Os encontros de alcance mundial não só permitem que diversos países, dentre eles o Brasil, discutam planos de ação conjunta face às indústrias fumageiras, como também contribuem para divulgar conhecimentos que são determinantes do posicionamento discursivo de diferentes atores sociais - tanto para aqueles 
que são a favor quanto para aqueles contrários às legislações anti-tabagistas7. Esses encontros de naturezas distintas produzem insumos que têm repercussão direta nas discussões presentes na cena midiática, como exploraremos a seguir. Os fóruns especializados, tais como os científicos, são fundamentais para o aprofundamento de determinadas questões, codificadas em linguagem especializada. Já a publicização dos casos de pessoas virtualmente atingidas e suas histórias de vida permitem a tematização de danos e sofrimentos, através de uma linguagem existencial que aproxima o debate de contextos densos da interação diária.

\section{Debate mediado e Estratégias discursivas}

O embate argumentativo em torno do cigarro, motivado, em grande medida, pela tramitação da Lei Antitabagista no Congresso Nacional, envolveu atores sociais diversos, portando diferentes estratégias de convencimento e afirmação. Alvo e participante do debate inerente à cena midiática, a indústria de cigarros esteve durante todo o período analisado em posição de desvantagem no fluxo concorrente dos campos argumentativos. No espaço da mídia, poucas vezes as empresas puderam colocar-se como agentes do discurso. A série de denúncias que recaíram sobre suas atividades e sua conduta, seu produto, suas declarações, colocaram-nas em posição de respondentes, cujos argumentos tiveram dificuldade de fazer frente às proposições dos demais atores sociais.

Para entendermos as dificuldades encontradas pelas companhias produtoras de cigarros em validarem seus projetos de fala, é fundamental apresentarmos, ainda que em linhas gerais, pontos importantes do debate antitabagismo, travado nas matérias dos jornais analisados. Os enquadramentos discursivos que ganharam visibilidade e durabilidade na

\footnotetext{
7 A própria Souza Cruz promoveu encontros em que diversos atores sociais envolvidos na problemática do fumo puderam apresentar seus posicionamentos discursivos, diante dos quais a empresa organiza seu projeto de fala.
} 
cena midiática foram articulados a partir de dois argumentos principais: o econômico e o da saúde pública. Os pacotes interpretativos ${ }^{8}$ assim delimitados permitiram aproximar atores sociais diversos que compartilhavam posições, compondo um cenário amplo e complexo de disputa discursiva.

\section{O Argumento Econômico}

O argumento econômico serviu de idéia central para dois enquadramentos discursivos defendidos pela indústria produtora de cigarros e pelos grupos contrários à legislação antitabagista. $\mathrm{O}$ primeiro enquadramento argumentativo pode ser assim resumido: as ações restritivas do Estado contrariam o equilíbrio do mercado. Proibir a propaganda de derivados do tabaco é considerado, nesse ordenamento de sentido, uma ação que agride os mecanismos de mercado, os quais incluem, além da produção e da comercialização, a divulgação dos bens.

A proibição da publicidade dos derivados de tabaco, na opinião da Associação Brasileira de Agências de Publicidade (ABAP) e da Souza Cruz., perturbaria as relações de concorrência, dificultando a entrada de novas empresas produtoras de cigarros. A impossibilidade de dispor dos mecanismos de construção de marca privilegiaria as empresas já existentes, que durante um longo período puderam investir em branding. Por outro lado, o enfraquecimento das marcas facilitaria a expansão do mercado ilegal, ao tornar os produtos "indiferenciados".

Ao apresentarem seus argumentos na cena midiática, esses atores buscaram deslocar a questão da proibição da publicidade de derivados de

\footnotetext{
${ }^{8}$ Segundo Gamson e Modigliani (1989: 3), o discurso midiático pode ser definido como uma série de pacotes interpretativos que buscam dar sentido a uma questão. Tais pacotes possuem uma idéia central que delimita o campo interpretativo, definindo posições e buscando dar sentido aos eventos relevantes em debate. Sobre enquadramentos na mídia, ver também Gamson (1992), Entman (1993), Reese et al (2003).
} 
tabaco para um plano mais amplo, além do simples interesse das agências e da Companhia na preservação dos lucros. A estratégia discursiva da ABAP opta por defender o mercado, tanto como um espaço concreto de comercialização, quanto como um valor que deve ser preservado. Trata-se de uma tentativa de adequação do discurso ao plano da esfera pública, em que os interesses coletivos devem ser garantidos. Junto a isso, a ABAP busca desvincular-se, publicamente, do peso negativo do fumo e das acusações que pudessem recair sobre as indústrias tabagistas.

$\mathrm{O}$ argumento apresentado pelo vice-presidente da ABAP, Dalton Pastore, sintetiza a idéia central que articula o enquadramento discursivo apresentado pela entidade: "Não dá para vetar só um elo da cadeia de produção"9. E conclui: "a única novidade será o fim do surgimento de novas empresas de cigarro"10.

A Souza Cruz, por sua vez, utiliza-se de uma estratégia discursiva que não nega o papel da propaganda como agenciadora de representações simbólicas, mas ressalta a importância do processo de construção das marcas para a garantia da qualidade do produto oferecido ao consumidor. Há, também aqui, a busca por parte do locutor de não ligar a defesa da opinião ao interesse exclusivo da empresa, mas ao interesse mais amplo, no caso, a preservação da legalidade e da qualidade dos produtos comercializados no mercado.

A estratégia de convencimento proposta pelo então presidente da Companhia Souza Cruz, Flávio Andrade, é exemplar: "a publicidade não aumenta o tamanho do mercado. Ela é feita com objetivos competitivos. $\mathrm{Ou}$ seja, para os consumidores darem preferência às minhas marcas em

\footnotetext{
${ }^{9}$ PENTEADO, Gilmar. Para entidades, veto não afetará consumo. Folha de São Paulo, São Paulo, 10 ago. 2000. p. C3.

${ }^{10}$ Ibid.
} 
detrimento às do concorrente"11. E conclui: "Quando eu não puder mais falar sobre as minhas marcas, tanto as marcas vendidas legalmente como as ilegalmente serão muito parecidas"12. Este argumento fundamenta a opinião com que Flávio de Andrade pretende convencer o auditório: "A partir do momento em que se proíbe a publicidade, vamos criar condições para aumentar a ilegalidade no país" ${ }^{13}$.

O segundo enquadramento discursivo mobilizado em torno de argumentos econômicos ressalta o papel da atividade econômica como provedora de bem estar para a população. Com um apelo menos técnico que o do primeiro enquadramento, o campo de significação ligado ao impacto da atividade econômica na geração de progresso social tem um alcance potencial maior em relação ao auditório que se busca convencer. $\mathrm{O}$ enquadramento argumentativo da geração de bem estar social é bastante pragmático. Podemos resumi-lo da seguinte forma: a atividade industrial gera progresso econômico. $\mathrm{O}$ crescimento econômico provê novos empregos. Em virtude disso, há crescimento de renda da população, além da geração de impostos, que darão maior capacidade gerencial ao Estado de prover o bem estar de forma ampla. Esse campo argumentativo foi utilizado nas estratégias discursivas, por exemplo, da bancada parlamentar contrária à Lei Antitabagista, além da Associação Brasileira da Indústria do Fumo (ABIFUMO).

Esse quadro de referência argumentativo sustenta-se em um cenário bastante condizente com o discurso proposto pela empresa. A indústria

\footnotetext{
${ }^{11}$ REIS, Cléber Cabral. Contrabando de cigarro cresce. Jornal do Brasil, 20 ago. 2000. p. 12. (Entrevista Flávio de Andrade).

${ }^{12}$ Ibid.

${ }^{13}$ Entrevista com Flávio de Andrade publicada no Jornal do Brasil, no domingo, 20 de agosto de 2000. A matéria ocupou uma página inteira do jornal, no caderno 1. A publicação da entrevista coincide com a votação do Projeto de Lei na Câmara Federal. $\mathrm{O}$ grande espaço destinado à Souza Cruz destoa, quando comparado à cobertura do próprio jornal ao longo do período analisado e, especialmente, do espaço ocupado pela Companhia nas matérias que trataram da questão do fumo, na Folha de S. Paulo e no Estado de Minas.
} 
tabagista é realmente um dos maiores pagadores de impostos do Brasil. Em 1999, foram recolhidos, em tributos, cerca de R $\$ 5,5$ bilhões, segundo a ABIFUMO. Se considerarmos o fato de a Souza Cruz ser a líder no setor de cigarros, com quase $80 \%$ de mercado doméstico, podemos deduzir o tamanho de seu peso econômico. Segundo dados do Relatório Social 2001 da companhia, sua atuação gera quase 5 mil empregos diretos e aproximadamente 380 mil indiretos. Cerca de 45 mil famílias de produtores de fumo fornecem matéria prima para a Souza Cruz. Sem dúvida, esses dados são bastante significativos e dão consistência às formulações propostas.

A defesa do enquadramento da promoção econômica e social é um dos pilares da estratégia argumentativa da Souza Cruz. Isso é particularmente evidente no conteúdo do site da empresa na Internet. No espaço destinado à fala da indústria tabagista, nas matérias analisadas, o enquadramento da promoção social poucas vezes é acionado diretamente pelo falante. Ao que parece, as implicações de bem estar social gerado pelo impacto econômico é considerado consensual pela empresa, o que se apresenta, então, como dado, um implícito qualificativo para outros enquadramentos propostos.

Há, entretanto, exceções. Uma situação em que a indústria tabagista aciona diretamente o enquadramento da promoção econômica e social é mostrada no polêmico estudo realizado pela Philip Morris. Nele, a empresa ressalta os benefícios econômicos do cigarro para as finanças públicas da República Tcheca, obtidos pela arrecadação de impostos. Até aí, nada de novo presente na proposição. Entretanto, a gigante americana da indústria do tabaco propõe um reenquadramento argumentativo: o "impacto positivo" do cigarro ocorreria, também, em virtude da "economia de gastos na área da saúde pela mortalidade precoce" 14 .

${ }^{14}$ MORTE de fumante ajuda economia, diz Philip Morris. Folha de S. Paulo, São Paulo, 17 jul. 2001. p. A9. 
$\mathrm{O}$ argumento aciona um terreno polêmico, reconhecido pelo porta-voz da empresa na Suíça, Réme Calvet, ao assumir que o informe "pode parecer muito chocante"15. Sabendo, portanto, do impacto negativo do reenquadramento proposto, a Philip Morris apressa-se em justificar-se, buscando desvincular o campo de significações proposto daquele ligado a outros valores que não sejam econômicos. Segundo Calvet, o objetivo da pesquisa “'não é entrar em uma polêmica', mas que ela seja usada como ponto de referência econômico"16. O porta-voz da divisão internacional da Philip Morris, Robert Kaplan, reitera que o propósito do novo relatório é ser "nada mais, nada menos que um estudo de impacto econômico"17. A opinião que a empresa propõe no corpo do relatório, a de que para "a economia do Estado a morte precoce dos fumantes é vantajosa"18, é uma decorrência pragmática do reenquadramento argumentativo proposto. Mario César Carvalho, no livro $O$ Cigarro, realça, por analogia, o absurdo do estudo apresentado pela indústria tabagista. "Seria algo como medir os ganhos financeiros com a distribuição de veneno de rato na merenda escolar das crianças" (Carvalho, 2001, p.78). Ao contrapor a vantagem econômica ao valor da vida, a empresa transforma esta última em mercadoria - que deve ser tratada numa lógica financeira - o que evidencia a incapacidade dos mecanismos de regulação sistêmica de darem conta de domínios que envolvem valores e demandas éticas. Argumentos como os relatados - que podem, no campo estrito do saber econômico, parecer lógicos e pertinentes são totalmente indefensáveis quando submetidos ao campo discursivo da esfera pública e suas condições de validação.

O enquadramento discursivo baseado no argumento econômico não foi tão forte quanto se poderia pensar, se levássemos em consideração unicamente o poderio das empresas produtoras de cigarros. Na cobertura feita pelos jornais analisados, em nenhuma das matérias veiculadas o argumento

15Ibid.

${ }^{16}$ Ibid.

${ }^{17}$ Ibid.

${ }^{18}$ Ibid. 
econômico conseguiu um status de verdade, ou seja, mostrou-se como algo que não necessitasse ser questionado. Pelo contrário, seu poder de convencimento no embate argumentativo, em que os locutores buscam a adesão do outro apresentando razões e justificativas, foi bastante contestado, tendo encontrado, portanto, muita dificuldade em legitimar-se.

Grupos antitabagismo mobilizaram contra-argumentos que ressaltam os custos do cigarro para o sistema de saúde, derivados de doenças relacionadas ao fumo. Os defensores da legislação antitabagista buscam convencer o auditório de que, mesmo considerado o grande volume de impostos gerado pelo cigarro, o prejuízo para o sistema de saúde e as perdas de produtividade no trabalho provocadas pelo fumo são enormes. Tal reenquadramento, organizado dentro própria lógica econômica, atinge diretamente o argumento da promoção social e econômica, uma vez que refutam-se as alegadas vantagens tributárias das empresas e as riquezas assim geradas para o país. Os militantes antifumo apresentam valores expressivos para evidenciar que as despesas para o Estado são maiores que os ganhos ${ }^{19}$.

A situação no Brasil pode ser mensurada a partir da matéria do dia 27 de junho de 2000, veiculada na Folha de S. Paulo: segundo estimativa publicada pela Folha, foram gastos no ano passado R $\$ 3,43$ bilhões do dinheiro do contribuinte com problemas de saúde e outros gastos provocados pelo fumo. No mesmo período, o governo teria arrecadado $\mathrm{R} \$ 2,18$ bilhões em impostos sobre esses produtos. ${ }^{20} \mathrm{~A}$ fala do deputado Jutahy Magalhães Júnior (PSDB-BA), na matéria publicada no jornal Folha de S. Paulo, aponta esse ônus para as finanças do Estado, como contraponto ao argumento do custo

\footnotetext{
19 Um exemplo é a pesquisa divulgada pelo Ministério da Saúde dos EUA, em 1985, que estimava o custo total do cigarro para a sociedade americana em torno de US\$ 65 bilhões. Segundo a pesquisa, para cobrir o gasto com a saúde, o maço teria de custar praticamente o dobro do preço médio corrente.

${ }^{20}$ SALOMON, Marta. Lobby pode impedir proibição de propaganda. Folha de São Paulo, São Paulo, 27 jun. 2000. p. C1.
} 
econômico da lei apresentado pela bancada ruralista do Rio Grande do Sul. “Em dois a três anos, a economia para o SUS (Sistema Único de Saúde) será de $\mathrm{R} \$ 2$ bilhões a R $\$ 3$ bilhões" ${ }^{21}$. Ao desqualificar o argumento da geração de riqueza, desqualifica-se um dos pilares da estratégia argumentativa defendida por empresas tabagistas e os grupos sociais interessados na não aprovação da lei, apresentada tanto nas discussões no Parlamento quanto no embate discursivo mais amplo.

Essa contra-argumentação, de conteúdo técnico e baseado na lógica do mercado, evidencia ainda que a força que move o mercado é a do consumo e que este não é imutável. Se há diminuição de demanda por um produto, esta será deslocada para outro bem. Desta forma, a arrecadação tributária é preservada, não havendo a necessidade de particularizar ou privilegiar determinado ramo produtivo. A afirmativa do então ministro da Saúde resume bem esse enquadramento argumentativo: "Serra considera 'imbecil' o argumento de que o cigarro não deva ser combatido porque propicia a arrecadação de bilhões de reais. "O dinheiro que seria usado para comprar cigarros será gasto em outros produtos, que também recolhem impostos, diz o ministro" 22.

Além disso, os grupos antitabagismo buscaram ressaltar incoerências entre o discurso público das empresas e as evidências de práticas ilegais cometidas pelas mesmas. A força desse enquadramento discursivo está principalmente no fato de atingir o "caráter" da indústria tabagista, sua qualidade de agente social dotado de credibilidade. A fonte principal das denúncias de irregularidade nas práticas relacionadas à produção e à comercialização dos derivados de tabaco provém, principalmente, de documentos secretos das empresas, levados a público a partir dos anos 90.

${ }^{21}$ OLIVEIRA, Valéria de. Câmara aprova veto à publicidade de tabaco. Folha de $S$. Paulo, São Paulo, 10 ago. 2000. p. C1.

${ }^{22}$ CONTI, Mario Sergio. Governo inicia guerra contra a propaganda de cigarros. Folha de São Paulo, São Paulo, 04 jun. 2000. p. C4. 
Denúncias de envolvimento em atividades do mercado ilegal de cigarros, de manipulação genética para produção de nicotina super potente, ocultação de informações relevantes para a saúde do consumidor, como aquelas relacionadas à dependência e à relação causal entre fumo e câncer, comprometeram o projeto de fala das empresas, com a força devastadora da própria letra. As incoerências entre o discurso público da empresa tabagista $\mathrm{e}$ as evidências de práticas ilegais acabam por deslegitimar a sua fala, ao comprometer uma das condições fundamentais do discurso, isto é, a pretensão de veracidade (Habermas, 1989) . Os grupos antitabagismo visam, dessa forma, desenvolver uma estratégia argumentativa que desqualifica a atividade produtiva, não por ela mesma, já que é legal, mas pelo seu efeito (vício/dependência) e pela identidade e "caráter" de quem a pratica (demanda ético/moral).

\section{O Argumento da Saúde Pública}

O segundo pacote interpretativo presente no fórum concorrente de debate nos jornais foi o argumento da saúde pública. Defendido pelos grupos favoráveis às políticas públicas restritivas ao fumo, os enquadramentos decorrentes dessa base argumentativa destacam aspectos médico-biológicos e comportamentais. Há uma relação intensa entre esse campo de sentido e os aspectos econômicos que ressaltam o ônus do cigarro para o Estado.

Nesse campo destacam-se, na cobertura dos jornais, entidades como a Organização Mundial de Saúde (OMS), o Ministério da Saúde, o Instituto Nacional do Câncer (INCA), além de especialistas e de outras instituições da área de saúde. Tais instituições e atores sociais compartilham de posições e estratégias discursivas muito semelhantes. Eles utilizam preferencialmente o discurso científico e, portanto, buscam situar-se mais próximos do campo da demonstração como modo de convencimento, valendo-se de dados estatísticos, em resultados de pesquisas científicas. 
Essas pesquisas foram largamente noticiadas pelos jornais analisados, sendo que os dados sobre os males causados pelo cigarro ao organismo do fumante mostram-se contundentes o suficiente para justificar a relevância das reivindicações apresentadas pelos grupos e entidades envolvidas no debate sobre o antitabagismo:

A Organização Mundial de Saúde registra mais de 60 mil pesquisas publicadas que comprovam a relação causal entre o uso do cigarro e doenças como câncer de pulmão ( $90 \%$ dos casos), enfisema pulmonar (80\%), infarto do miocárdio (25\%), bronquite crônica e derrame cerebral (40\%). ${ }^{23}$

A demonstração, como estratégia de convencimento dominante, fica evidente na citação seguinte:

Há algum tempo, a dependência da nicotina, principal causa do vício, vem sendo tratada como doença física e psíquica. A OMS (Organização Mundial da Saúde) calcula que, em todo o mundo, exista 1,2 bilhão de fumantes. Embora $70 \%$ manifestem o desejo de parar, apenas $5 \%$ conseguem sozinhos. Parece pouco, mas representa $90 \%$ dos casos vitoriosos. ${ }^{24}$

Questões como dependência, vício, fumo passivo e relação direta entre tabagismo e doenças sérias são tratadas através de discursos de especialistas, os quais, como sabemos, conseguem um efeito de credibilidade também muito forte na cena pública. Afinal, é bastante consensual, ainda mais entre os leigos, a autoridade da ciência em prover verdades, permitindo transformar uma afirmação, ou enunciado, em um "fato estabelecido" que ninguém poderá questionar, a menos que se oponha a ele um outro enunciado, melhor demonstrado. Além disso, os jornalistas costumam acionar médicos e diversos profissionais da área de saúde com o objetivo de informar, como é habitualmente concebido o propósito do discurso científico. Mas há nas afirmações dos especialistas, muitas vezes, uma finalidade prática a ser atingida: à conscientização e o esclarecimento sobre os males do fumo, visando ao convencimento ou persuasão do interlocutor.

23FUMO começa na idade escolar. Folha de S. Paulo, São Paulo, 25 abr. 2000. p. 3-1. 24JORGE, Mariliz Pereira. O fantasma da recaída. Folha de S. Paulo, São Paulo, 23 jul. 2000. p. C6. 
Tal deslocamento da questão do fumo para o domínio médico e sua abordagem como problema de saúde pública, na cena midiática, torna a participação da Companhia Souza Cruz bastante difícil nesse domínio. Se no debate inerente à cena midiática coube à Souza Cruz o papel de respondente, com pouca possibilidade de afirmação de seus posicionamentos face à polêmica em torno do ato de fumar, o caminho encontrado pela Companhia foi buscar apresentar seu projeto de fala em seu site na Internet.

A estratégia de convencimento sustenta-se basicamente nos valores da individualidade e da liberdade de expressão, além da intensa preocupação em demonstrar sua qualidade gerencial e produtiva, somada ao peso econômico e social da Companhia, caracterizada como uma multinacional genuinamente brasileira. A fim de dar solidez aos atributos identitários apresentados, o discurso do site da Companhia busca responder às acusações graves que lhe são endereçadas no domínio público. Dois pontos são fundamentais em sua estratégia discursiva: a definição do fumante como indivíduo enquanto singularidade e não-repetibilidade e a defesa do conceito do consumidor racional.

O foco na particularidade de cada pessoa serve para compor a estratégia de esvaziamento do potencial de causalidade das pesquisas científicas sobre males do fumo. O discurso do site não nega a relação entre fumo e doenças graves, mas faz a importante ressalva de que os estudos científicos são estatísticos, ou seja, referem-se a grupos de pessoas e não a indivíduos isoladamente: "os estudos estatísticos não são capazes de identificar o que irá acontecer a uma determinada pessoa, e a ciência ainda não é capaz de determinar quais fumantes irão adoecer ou não"25. Através desse procedimento retórico, a empresa pretende desvincular do ato de fumar a idéia de causalidade direta em relação às doenças graves quando se trata do indivíduo, do consumidor, isoladamente.

${ }^{25}$ Disponível em: <http://www.souzacruz.com.br>. Acesso em: 17/07/2003. 
Outra característica atribuída pelo discurso do site ao consumidor da Souza Cruz é sua capacidade de tomar decisões conscientes. Ele seria dotado de intencionalidade, ou seja, seria capaz de agir de forma racional, pois, segundo o discurso da empresa, possui informação suficiente e sabe como bem articular suas ações para que sejam refletidas, e não impulsivas. É exatamente para dar consistência a essa concepção racional do fumante que a Souza Cruz define seu público-alvo como sendo formado por adultos bem informados e capazes de bem dosar seu consumo de cigarros, estabelecendo o equilíbrio entre o prazer e o risco. "A Souza Cruz fabrica cigarros para o consumo exclusivo de adultos [...]"26. E, reafirma, "O cigarro é um produto que não deve ser consumido de forma inconseqüente, e sim apreciado com bom senso e razão, por pessoas adultas e bem informadas”27.

Apesar de o discurso da empresa atribuir aos posicionamentos assumidos um tom de fechamento, como se a argumentação apresentada fosse suficiente para encerrar a polêmica, isso está longe de acontecer. Excetuando apenas a capacidade gerencial da Souza Cruz, as respostas e os esclarecimentos foram e são questionados pelos diversos grupos e entidades presentes no debate sobre os males causados pelo cigarro.

\section{Conclusão}

Na medida em que as empresas têm suas práticas questionadas por setores variados da sociedade, elas sofrerão resistências que não são advindas do campo mercadológico. As questões tematizadas nos espaços públicos exercem pressões sobre os centros decisórios do Estados democráticos, sendo, muitas vezes, encampadas pelos complexos parlamentares ou pelos tribunais. Podem, portanto, resultar em normas jurídicas com larga base de legitimidade, além de gerar inovações culturais e institucionais mais amplas. O envolvimento de setores da sociedade civil e a densa problematização da

$$
\begin{aligned}
& { }^{26} \text { Ibid. } \\
& { }^{27} \text { Ibid. }
\end{aligned}
$$


questão do fumo pelos mídia permitiram conferir ao embate argumentativo uma dimensão propriamente pública, distinta da regulação produzida pela lógica estrita do mercado ou do Estado. Pouco importa, nesse caso, se as demandas tiveram origem na sociedade civil ou nos próprios centros políticos. O relevante para produzir legitimidade e garantir maior grau de cooperação democrática entre os atores sociais é a possibilidade de os problemas detectados passarem pelo crivo de um debate ampliado.

Nesse sentido, o valor da publicidade deve ser destacado. Ao serem convocados a interagir de forma complexa com vários discursos que estão presentes na esfera pública, os atores sociais - sejam os conglomerados empresariais (tal como a Souza Cruz), sejam os agentes do Estado ou ainda aqueles da sociedade civil - percebem que seus projetos de fala não podem ser desenvolvidos como se estivessem em contextos isolados, fechados em seus próprios círculos de interesse. Há sempre uma dinâmica de trocas e influências recíprocas e construção conjunta de formas interpretativas da realidade. De tal sorte, acreditamos que a passagem pela mídia contribui para promover a ampliação do debate, com a generalização das temáticas em público, o que é extremamente relevante para o processamento cognitivo e coletivo de problemas de interesse comum.

No espaço de concorrência discursiva dos debates internos à cena midiática, nem todos os pacotes argumentativos apresentados por atores sociais são igualmente potentes. Os campos de sentido defendidos pelos militantes antifumo não apenas sofreram pouquíssima contestação quanto eles próprios proporcionaram diversas informações que foram utilizadas como dados contextuais nas matérias analisadas. O posicionamento favorável dos jornais analisados aos principais campos interpretativos propostos pelos grupos antitabagismo foi claramente expresso em diversos editoriais sobre a questão ${ }^{28}$.

${ }^{28}$ HORRORES do Cigarro. Folha de S. Paulo, São Paulo, o1 jun. 2001. p. A2. 
O agenciamento de sentido e os enquadramentos propostos pela mídia encontram explicação em diversos fatores presentes no campo extramidiático, como diversos autores sustentam (Meyer, 1995; Klandermans e Goslinga, 1996; McAdam, 1996; Pan e Kosicki, 2003). No caso do debate bem como a negociação e a barganha - envolvidos na questão do fumo transcenderam, em muito, os limites dos sub-sistemas funcionais autônomos, aparentemente independentes em relação à sociedade. O poderio econômico dos produtos de cigarros não foi em si condição suficiente para transformar-se em poder político capaz de influenciar e, no limite, definir as decisões nas instâncias institucionalizadas. É possível dizer que a empresa demonstrou competência em construir seus argumentos na esfera pública, levando em consideração demandas éticas e morais, bem como a busca de entendimento baseado no interesse comum - recursos procedimentais característicos do espaço público. Os atores, protestando contra a legislação antitabagista, preocuparam-se, sempre, em desvincular as proposições apresentadas de interesses particulares. Procuraram, por exemplo, defender o equilíbrio de mercado e a promoção econômico social gerados pela atividade empresarial, e não a preservação de sua margem de lucro ou de sua base eleitoral, no caso de parlamentares que lucravam com o desenvolvimento das empresas fumageiras.

Ao proceder dessa forma, a empresa faz campanha a favor de seus interesses, utilizando razões capazes de mobilizar convicções racionalmente motivadas. O conteúdo discursivo do site da Souza Cruz seguiu este mesmo caminho, ao buscar apresentar a empresa como um ator público responsável, que zela pela qualidade de seu produto, tratando de diminuir o índice de substâncias danosas no cigarro, e que, além disso, mostra-se interessado em participar do debate sobre o fumo (Santiago, 2003). A preocupação com as condições de validação de seu discurso na esfera pública transparece ainda no FUMO Cívico. Folha de S. Paulo, São Paulo, 22 jul. 2001. p. A2. 
apelo aos valores de expressão e de autonomia de um consumidor racional, com liberdade de escolha e capaz de responder, com probidade, pelos seus próprios atos - valores intrinsecamente associados ao projeto democrático.

Contudo, tais habilidades não foram suficientes para reverter o cenário de adversidades enfrentado pela indústria tabagista - o qual se expressou também na cena midiática. A atuação consistente de grupos ligados ao movimento antitabagismo no espaço público foi capaz de articular amplos consensos sobre os males causados pelo cigarro. Tais grupos não só despontencializaram, i.e, retiraram o poder de convencimento dos argumentos apresentados pelos defensores do fumo no próprio campo econômico, como também reforçaram a crise de credibilidade vivenciada pelas empresas de cigarros em virtude da publicização de documentos secretos que expuseram ações de bastidores que contradiziam o discurso público encetado por elas. É possível dizer, assim, que tais atores críticos foram bem sucedidos em modificar o contexto em que a deliberação mesma ocorre.

No caso do Brasil, o cenário favorável aos grupos antitabagismo na mídia já estava composto desde o início da intensificação da polêmica, por ocasião do envio do projeto de lei ao Congresso. Os males causados pelo fumo à saúde, os resultados de pesquisas científicas, bem como os embates travados nos tribunais americanos e ainda o conteúdo dos documentos secretos já vinham sendo amplamente tratados pelos mídia, no país. Nesse sentido, o sucesso do projeto de convencimento dos grupos antitabagismo no Brasil não pode ser analisado como um acontecimento limitado ao contexto local. O movimento antitabagismo organiza-se em rede no plano transnacional, com o propósito de intercambiar experiências e processar regulamentações normativas e jurídicas específicas. Tem, a seu lado, organizações influentes como a Organização Mundial de Saúde, a qual funciona como elemento de integração dos grupos antitabagismo, ao disponibilizar estudos científicos, 
diagnósticos e estatísticas a respeito de diversas questões relacionadas ao fumo.

Resta salientar que a aceitação favorável das opiniões apresentadas pelos militantes anti-fumo deve-se, ainda, ao fato de os pacotes interpretativos ligarem-se de forma direta aos apelos de qualidade de vida e aos pressupostos morais presentes na imagem da função pública das regulamentações jurídicas. Nesse sentido, as histórias de vida dos fumantes que entraram com ações nos Tribunais ou daqueles que expõem os males do cigarro no próprio corpo e os prejuízos daí decorrentes aproximam de modo direto o debate público da vida cotidiana, com maior permanência e impacto que as questões técnicas, relativamente abstratas.

Sob tal aspecto, os limites entre a esfera pública - composto por um público de pessoas privadas - e o mercado mostram-se muitos próximos. Os questionamentos públicos impuseram fissuras na aura glamourizada do cigarro e os constrangimentos associados ao ato de fumar comprometeram, em muito, o projeto de convencimento desenvolvido pelas empresas tabagistas (desenvolvido em seu site, por exemplo). Se considerarmos que as empresas não podem mais contar com os instrumentos de comunicação mercadológica, como manter o universo associado ao cigarro sem o recurso à política de branding corporativo?

Mais que uma inovação institucional, organizada pelos complexos parlamentares e jurídicos, as questões presentes no debate antitabagismo foram capazes de gerar relevante inovação cultural (Bohman, 1999, 2000; Drysek, 2002). As empresas tabagistas estão sujeitas a esse novo cenário, que interfere diretamente nas suas ações mercadológicas. Mesmo com todo o poderio dos complexos transnacionais dos produtores de cigarro, as sociedades democráticas impuserem fortes contrapartidas às ações das empresas, a partir da mobilização dos espaços públicos e dos complexos estatais. E para obter sucesso em tal processo, o papel da mídia e a criação de 
redes comunicativas capazes de sustentar o debate crítico em público é fundamental.

Fica evidente a relevância dos mídia para editar e ampliar o debate público. Apesar de ser um caso específico, o debate público sobre o tabagismo e seus resultados tanto em termos jurídicos quanto culturais desafia visões céticas, que desconfiam do poder de mobilização e de resistência das sociedades complexas face aos complexos transnacionais. Esse caso ressalta o valor da deliberação e da publicidade, ao evidenciar que a participação dos públicos críticos nos debates sobre questões de interesse comum fortalece o papel do Estado face às grandes empresas. Dentro de uma estrutura mais dualista e dinâmica do sistema político, visando uma cooperação constante entre as esferas formais e informais, é possível verificar a conquista suficiente de poder legítimo no processo deliberativo, com o propósito de alcançar metas coletivas.

\section{Referências:}

BENHABIB, Seyla.(1996). 'Toward a Deliberative Model of Democratic Legitimacy'. in S. Benhabib (ed.). Democracy and Difference. Princeton: Princeton University Press.

BOHMAN, James (2000). Public Deliberation: Pluralism, complexity and Democracy. Massachusetts: MIT press.

BOHMAN, James (1999). Citizenship and Norms of Publicity. Wide Public Reason in Cosmopolitan Societies. Political Theory. Vol. 27, no2, , pp. 176202.

BLUMER, Jay G. e GUREVITCH, Michael. Rethinking the Study of Political Communication. IN: CAMAUËR, Leonor (2000). Women's movements, public spheres and the media: a research strategy for studying Women's movements publicist strategies. In: SREBERNY, A. e L.VAN ZOONEN. Gender, Politics and Communication. New Jersey: Hampton Press, p. 161-182

CURRAN, James \& GUREVITCH, Michael (eds.) (2000).Mass Media and Society. Oxford: Oxford University Press, $3^{\text {rd }}$ ed., pp.155-174.

CARVALHO, Mário César (2001). O Cigarro. São Paulo: Publifolha. 
CHARAUDEAU, Patrick. Para uma Nova Análise do Discurso (1996). In: CARNEIRO, Agostinho D. (Org.). O Discurso da Mídia. Rio de Janeiro: Oficina do Autor, p. 5-43.

CHESNEAUX, Jean. Modernidade Mundo (1995). Petrópolis: Vozes, pp. 135157

COHEN, Joshua (1997). Deliberation and Democratic Legitimacy. In: BOHMAN, J.; REHG, W. (Eds.). Deliberative democracy. London: MIT Press, p. 67-92.

CURRAN, J. (1991)Rethinking the media as a public sphere. In P. DAHLGREEN and C. SPARKS (orgs.). Communication and Citizenship: Journalism and the Public Sphere in the new media age. London, Routledge, p. 27-57.

DEWEY, John [1927], (1954) The Public and its problems. Athens: Swallow Press.

DRYZEK, John S. (2002) Transnational Democracy: Beyond the Cosmopolitan Model. In: DRYZEK, John S. Deliberative Democracy and Beyond. Oxford: Oxford University Press, p. 115-139.

ENTMAN, Robert (1993). Framing toward a clarification of a fractured paradigm. Journal of Communication, 43(4), 51-58.

GAMSON, William (1992). Talking Politics. Cambridge: Cambridge University Press.

GAMSON, William, MODIGLIANI, Andre (1989). Media Discourse and Public Opinion on Nuclear Power: a Constructionist Approach. American Journal Of Sociology, Chicago, The University of Chicago, v. 95, n. 1, p. 137 , July.

GIDDENS, Anthony (2001). A Terceira Via e seus Críticos. Rio de Janeiro: Record.

GOMES, W. (2004) A Política em Cena e os Interesses fora de Cena. IN: Transformações da Política na Era da Comunicação de Massa. São Paulo: Paulus, pp.129-170.

GUIBERNAU, Montserrat (2001). Globalization, Cosmopolitanism, and Democracy: an interview with David Held. Constellations, v.8, n. 4, p. 427-441.

GUTMANN, Amy; THOMPSON, Dennis (1996). Democracy and Disagreement .Cambridge: Harvard University Press.

HABERMAS Jürgen (1984). Theory of Communicative Action, v. I, New York: Beacon Press.

HABERMAS, Jürgen (2001). A Constelação Pós-nacional. São Paulo: Littera Mundi. 
HABERMAS, Jürgen (1997). Direito e Democracia: entre Facticidade e Validade. Rio de Janeiro: Tempo Brasileiro,. v. I e II.

IANNI, Octávio (1999). A Era do Globalismo. 4. ed. Rio de Janeiro: Civilização Brasileira.

IANNI, Octávio (1999) Teorias da Globalização. 5. ed. Rio de Janeiro: Civilização Brasileira, 1999.

KLANDERMANS, Bert e GOSLINGA Sjoerd (1996). 'Media discourse, movement publicity and the generation of collective frames: Theoretical and empirical exercises in meaning construction. In McADAM, Doug et al. Comparative perspectives on social movement. Cambridge: Cambridge University Press, 1996, p. 312-337

KLEIN, Naomi. (2002) Sem logo: a Tirania das Marcas em um Planeta Vendido. 2. ed. Rio de Janeiro: Record.

LEADER, Sheldon. (2001).The Reach of Democracy and Global Enterprise. Constellations, v. 8, n. 4, p. 538-553,.

MAIA, Rousiley C. M. (2004) Dos Dilemas da Visibilidade Midiática para Deliberação Política. In: LEMOS, A. Midia.Br. Porto Alegre: Sulina, 2004.

McADAM Doug (1996). 'Movement Strategy and Dramaturgic Framing in Democratic States: The Case of the American Civil Rights Movement'. in S. CHAMBERS and A. COSTAIN (eds.) Deliberation, Democracy and the Media. New York, Rowman \& Littlefield Publishers, p. 117-134

McCOMBS, Maxwell and GHANEM, Gerald (2003). 'The convergence of Agenda Setting and Framing'. in Stephen D. REESE et al. (eds). Framing Public Life: Perspectives on Media and our Understanding of the Social Life. New Jersey: Lauwrence Erlbaum Publishers, p. 67-82.

MEYER, D. S (1995). Framing National Security: Elite discourse on nuclear power during the Cold War. Political Communication. 12, 173-192.

NORRIS, Pippa (2000), A Virtuous Circle - Political Communications in Postindustrial Societies. Cambridge: Cambridge University Press.

PAN, Zhogdang e KOSICKI, Gerald M. (2003) "Framing as Strategic Action in Public Deliberation”. pp.35-66. in Stephen D. REESE et al. (eds). Framing Public Life: Perspectives on Media and our Understanding of the Social Life. New Jersey: Lauwrence Erlbaum PAGE, Benjamim (1996). Who deliberates? Mass media in Modern Democracy. London: University of Chicago Press.

PLOT, Martín. (1999)Deliberative Scenes and Democratic Politics in the Lewinsky Case. Constellations. Vol. 6, number 2, p.167-176. 
REESE Stephen D. et al. (eds) (2003) Framing Public Life: Perspectives on Media and our Understanding of the Social Life. New Jersey: Lauwrence Erlbaum Publishers.

RYAN, Charlotte (1991). Prime Time Activism: Media Strategies for grassroots organizing. Boston, MA: South End Press.

SANTIAGO, Daniela.(2003) Entre as Fronteiras do Debate Público e do Mercado: as Estratégias Discursivas da Companhia Souza Cruz. Belo Horizonte: Faculdade de Filosofia e Ciências Humanas da UFMG, 2003. 257 p.( Programa de Pós-graduação em Comunicação Social).

SANTOS, Milton.(2001) Por uma Outra Globalização: do Pensamento Único à Consciência Universal. 5. ed. Rio de Janeiro: Record.

SCHMAKZ-BRUNS, Rainer.(2001) The Postnational Constellation: Democratic Governance in the Era of Globalization. Constellations, v.7, n. 4, p. 554568.

THOMPSON, Dennis F (1999). Democratic Theory and Global Society. The Journal of Political Philosophy, v. 7, n. 2, p. 111-125.

ZOLO, Danilo (1992). Democracy and Complexity - A Realist Approach. Cambridge: Polity Press.

ZOZZOLI, Jean-Charles Jacques (1998). Compreensão da Significação Marcária - a marca, Instrumento e Reflexo da Produção Social de Sentidos; Transformação e Transação. IN: RUBIM, A.A.A. et al (org.). Produção e Recepção dos Sentidos Midiáticos. Petrópolis, Vozes, p.55-69. 